\title{
Association of household environment and prevalence of anemia among children under-5 in India
}

\author{
Annu Baranwal ${ }^{1}$, Anshu Baranwal ${ }^{2}$ and Nobhojit Roy ${ }^{1,3}$ \\ ${ }^{1}$ Environmental Health Resource Hub, School of Habitat Studies, Tata Institute of Social Sciences, Mumbai, India \\ 2 International Institute for Population Sciences, Mumbai, India \\ ${ }^{3}$ Department of Public Health Sciences, Karolinska Institutet, Stockholm, Sweden
}

\section{Edited by:}

Amit Agrawal, Gandhi Medical

College and Hamidia Hospital, India

Reviewed by:

Mladen Jasic, General Hospital Pula,

Croatia

Dayanand Bagdure, University of

Maryland School of Medicine, USA

*Correspondence:

Annu Baranwal, Environmental Health Resource Hub, School of Habitat

Studies, Tata Institute of Social

Sciences, Mumbai 400088, India

e-mail: baranwalannu@gmail.com
Objective: The study explores the association between the household environment and the prevalence of anemia among children under the age of 5 years in India.

Data and methodology: The study is based on 52,868 children under the age of 5 years, included in India's National Family Health Survey-3. The outcome variable was the prevalence of anemia. To understand the role of environment in determining child anemia, step wise logistic regression models consisting of environmental, child, socio-economic, and media exposure variables were applied.

Results: The occurrence of childhood anemia was higher in the North Eastern and Eastern regions compared to all other regions of India. Unclean fuel use, poor toilet facilities, staying in non-concrete house, exposure to smoking were important variables determining the prevalence of anemia. Smoking, when it was controlled with only socio economic factors, showed lesser impact on anemia, but when it got adjusted with socio-economic, child, and media variables together it showed an important impact as it increased the risk of anemia.

Conclusion: Children under 5 years of age generally stay inside their house and are more exposed to the household environment. Thus, among these children there are multiple risk factors causing anemia along with the nutritional deficiencies. Better resources are needed to educate the public and to increase awareness for improved hygiene, sanitation and housing facilities, health and nutrition, etc. Along with a wider program to manage nutritional deficiency, anemia in children $<5$ years, there should be a holistic approach toward anemia control inculcating household environmental conditions and socio economic determinants.

Keywords: children, anemia, environment, health, India

\section{INTRODUCTION}

Anemia is the major health problem in India especially among children and women. The National Family Health Survey (NFHS)-3 in India shows that around $70 \%$ of children are anemic in $<5$ years of age group and has increased around 5\% point from 1999 to 2006. Although there is high impact of background characteristics on severity of anemia, it is widespread in every group and every state. More than half of the children are anemic even if their mother has 12 or more years of education or is in highest wealth quintiles (1). Anemia is considered to be an important contributing factor to the global burden of disease. Affecting both developed and developing countries, it has an impact on not only human health and productivity but in the process it affects the socio-economic development of a nation. Though preventable, anemia still remains widely prevalent in the world. The WHO Global Database on Anemia estimated the prevalence to be $25 \%$ of the general population. It is known to affect all age groups, but pregnant women and pre-school children are at greater risk. It affects 1.62 billion people globally with about 293 million children under- 5 years (i.e., $47 \%$ of the affected population) and of this children population, more than $65 \%$ is in South-East Asia (this is second only to Africa) (2).
Anemia in children is influenced by structural and environmental factors, community, household factors, and individual's health and nutritional level. Anemia in pre-school children has a negative effect on cognition, motor development and growth, academic performance, immunity, and susceptibility to infections (3). These threats to health in earlier life are determinants of other health problems in later life (4).

Most of the previous studies done on anemia among children are based on socio economic and nutritional correlates. Very few studies have seen the combined effect of socio economic and environmental factors on anemia among children. This study thus examines the association of the household environment with the prevalence of anemia among children $<5$ years of age, in India.

\section{DATA SOURCE}

The data set used for this study was the NFHS-3 (2005-06). The NFHS is a large scale, multi-round survey conducted in a representative sample of households throughout India. Three rounds have been conducted since the first survey in 1992-1993. The survey provided state and national information for India on fertility, infant and child mortality, the practice of family planning, maternal and child health, reproductive health, nutrition, anemia, 
utilization, and quality of health and family planning services. Each successive round of the NFHS has had two specific goals: (a) to provide essential data on health and family welfare needed by the Ministry of Health and Family Welfare (MOHFW) and other agencies for policy and program purposes, and (b) to provide information on important emerging health and family welfare issues. The MOHFW, Government of India, designated International Institute for Population Sciences (IIPS), Mumbai, as the nodal agency, responsible for providing coordination and technical guidance for the survey. IIPS collaborated with a number of Field Organizations (FO) for survey implementation. Each FO was responsible for conducting survey activities in one or more states covered by the NFHS. Technical assistance for the NFHS was provided mainly by ORC Macro (USA) and other organizations on specific issues. The funding for different rounds of NFHS was provided by USAID, DFID, the Bill and Melinda Gates Foundation, UNICEF, UNFPA, and MOHFW, GOI. Information collected covered 52,868 children under the age of 5 years from a sample of 124,385 women between the ages of 15 and 49 years in all 29 states. (Children from ever married women included in the study.) Since anemia is a serious health problem in India, NFHS3 undertook direct measurement of the hemoglobin levels of all children under age 5 years, women age $15-49$ years, and men age 15-54 years. The prevalence of anemia among children was estimated by measuring the hemoglobin using the Hemo Cue ${ }^{\mathrm{TM}} \mathrm{Hb}$ $201+$ analyzer. This point-of-care quantitative hemoglobin testing system uses a single drop of blood from a finger prick (or heel prick in the case of infants under 6 months old), drawn into a curette, and then inserted into a portable, battery-operated instrument. To understand the household environment, a number of questions from the household questionnaire were asked to the head of the household. Figure 1 shows the conceptual framework for the study.

\section{VARIABLES AND METHODOLOGY EXPOSURE VARIABLES}

In this study, prevalence of anemia was calculated by four sets of variables, namely environmental variables, child related variables, socio-economic variables, and media exposure of women.

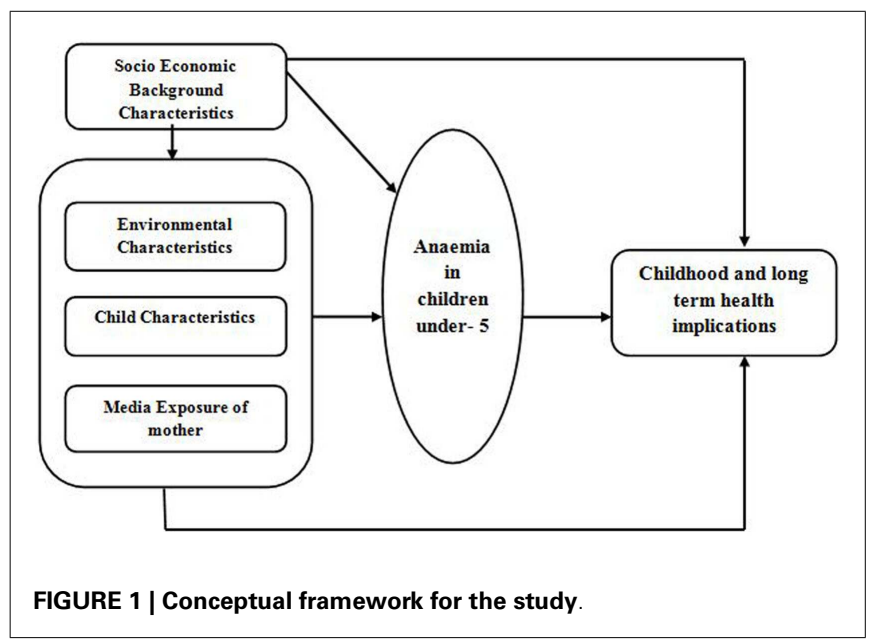

Environmental variables had seven main components, which were: source of drinking water (improved source of drinking water- piped water, piped into dwelling, piped to yard plot, public tap/stand pipe, tube well water, tube well or borehole, protected well, protected spring, rain water, bottled water; not improved source of drinking water-unprotected well, surface water, river/dam/lake/ponds/stream/canal/irrigation channel, tanker truck, cart with small truck), toilet facility (toilet facility available and toilet facility not available), type of house (Kaccha house - made from mud, thatch, or low quality materials, Semi pucca house - made from partly low quality and partly high quality material, Pucca house - made entirely from high quality materials including the floor, roof, and exterior walls), type of cooking fuel (clean cooking fuel - electricity, LPG/natural gas/biogas, kerosene; unclean cooking fuel - coal/ignite/charcoal, wood, straw/shrubs/grass, agricultural crop, animal dung), household structure (nuclear and non-nuclear), environmental tobacco smoke (ETS) (whether anyone in the house smoked - yes or no), and seasonality (winter, summer, and rains).

Child related variables included - sex of child (boy or girl), age of child ( $<6$ months, $6=23$ months, $24-59$ months), birth order of child (1-4), stunting (normal or stunted), duration of breastfeeding (never been breastfed, $<6$ months, 6 months and above, still being breastfed), treatment for parasitic infection (yes or no).

Socio-economic variables were - place of residence (urban, rural), caste (others, general, SC/ST, OBC), religion (hindu, muslim, others), mother's education (no education, primary, secondary, and above), mother's working status (not working, working), wealth index (rich, middle class, poor), geographical region: north (mainly the mountainous states along with states of northwest India that included plain and dry land), central (plain and plateau terrain), east, northeast (plain land and rugged terrain with hills and mountains), west (coastal plain, and plateau), and south (coastal plain and plateau).

Impact of media exposure on women was determined by whether they read newspapers/magazines or whether they watched television or heard radio. It was entered as "yes" or "no."

\section{OUTCOME VARIABLE}

Anemia was a dichotomous dependent variable where 1 was coded for those children who had anemia and 0 was otherwise. So the odds ratio explained the chance or probability of suffering from anemia according to the predictor variables.

To understand the role of environment in anemia in children, step wise logistic regression models consisting of environmental, child, socio economic, and media exposure variables were applied at all India level, making four consecutive models on SPSS package (version 20.0) (SPSS, Inc., Chicago IL, USA).

\section{RESULTS}

\section{BIVARIATE ANALYSIS}

Building environment: from Figure 2, it is inferred that none of the positive environmental factors were well beyond $30 \%$ of the provision of drinking water by pipe/tap/well; these figures were substantially lower in rural settings. Just about $30 \%$ of the population had improved toilet facilities (not shared flush and pit toilet) and used clean fuel (gas, electric, and kerosene) for cooking. 


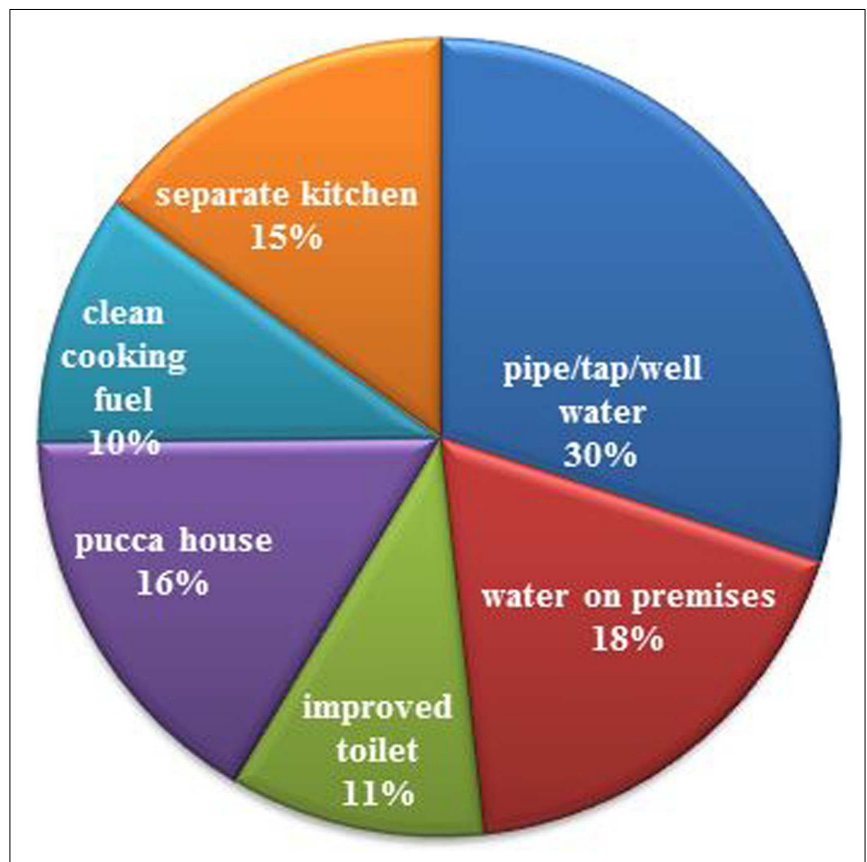

FIGURE 2 | Percentage of households by built environment.

Furthermore, it was observed in NFHS-3 that of those who used unclean fuel, i.e., coal, charcoal, crops residue, grass, dung cakes, etc., $91 \%$ used an open stove (chullah) not under a chimney.

\section{ANEMIA PREVALENCE}

Table 1 shows the prevalence of anemia by various predictor variables. Prevalence of anemia among children that lived in those households where there was no facility of toilet was found to be higher than those who had these facilities available. Type of house also made an important variable for anemia prevalence; high prevalence was seen among those children who lived in Kaccha or Semi Pucca houses. Children who stayed in households that used unclean fuel had higher anemic conditions than those in households that made use of clean fuel. $62.3 \%$ children reported to have symptoms of anemia were exposed to tobacco smoke in the house as against $60.9 \%$ children who did not experience tobacco smoking by anybody at home. Seasonality also had an effect on anemia; with a higher prevalence of anemia among children under-5 in summer and rainy season than in winter. Higher anemia levels could be seen among those children who lived in nuclear families than those who belonged to non-nuclear families.

Figure 3 shows the regional scenario of anemia prevalence among children under age of 5 years. At the all India level, the prevalence of the disease symptoms was $61 \%$. However, some distinct regional variation was observed. Eastern along with the north eastern region had the maximum prevalence of anemia, i.e., 69.7\%. Prevalence of anemia in North, Central, and West regions was around 56.5, 57.9, and 56.3\%, respectively. The southern region had some of the best performing states in social indicators with the prevalence of anemia, around $57.6 \%$ compared to all other regions.
Table 1 | Prevalence of anemia by selected characteristics among children under 5 years.

\begin{tabular}{|c|c|c|}
\hline \multirow[t]{2}{*}{ Characteristics } & \multicolumn{2}{|c|}{ Anemia in children under- 5} \\
\hline & $\%$ & $N$ \\
\hline \multicolumn{3}{|l|}{ Environmental } \\
\hline \multicolumn{3}{|l|}{ Toilet facility } \\
\hline Facility available & 55.1 & 9628 \\
\hline No facility & 63.9 & 19787 \\
\hline \multicolumn{3}{|l|}{ Type of house } \\
\hline Kaccha & 65.8 & 5329 \\
\hline Semi pucca & 63.5 & 14396 \\
\hline Pucca & 54.7 & 9614 \\
\hline \multicolumn{3}{|l|}{ Type of cooking fuel } \\
\hline Clean fuel & 51.6 & 4790 \\
\hline Unclean fuel & 62.8 & 24697 \\
\hline \multicolumn{3}{|l|}{ House structure } \\
\hline Nuclear & 62.6 & 15201 \\
\hline Non-nuclear & 59.2 & 15759 \\
\hline \multicolumn{3}{|c|}{ Smoking (anyone in the house) } \\
\hline No & 60.9 & 31823 \\
\hline Yes & 62.3 & 512 \\
\hline \multicolumn{3}{|l|}{ Source of drinking water } \\
\hline Improved & 60.2 & 26496 \\
\hline Not improved & 64.7 & 4399 \\
\hline \multicolumn{3}{|l|}{ Seasonality } \\
\hline Winter & 59.7 & 18815 \\
\hline Summer and rainy & 62.9 & 13526 \\
\hline \multicolumn{3}{|l|}{ Child } \\
\hline \multicolumn{3}{|l|}{ Sex of child } \\
\hline Boy & 60.2 & 16623 \\
\hline Girl & 61.8 & 15718 \\
\hline \multicolumn{3}{|l|}{ Age of child (months) } \\
\hline$<6$ & 67.3 & 3218 \\
\hline $6-23$ & 61.8 & 9080 \\
\hline $24-59$ & 59.1 & 17541 \\
\hline \multicolumn{3}{|l|}{ Birth order of child } \\
\hline 1 & 59.8 & 9609 \\
\hline 2 & 59.4 & 8567 \\
\hline 3 & 61.7 & 5296 \\
\hline 4 & 63.4 & 8869 \\
\hline \multicolumn{3}{|l|}{ Stunting } \\
\hline Normal & 59.0 & 15189 \\
\hline Stunting & 62.9 & 17160 \\
\hline \multicolumn{3}{|l|}{ Breastfeeding } \\
\hline Never breastfed & 61.5 & 1389 \\
\hline Less than 6 months & 59.3 & 2023 \\
\hline 6 months and above & 59.0 & 13816 \\
\hline Still breastfeeding & 62.9 & 14879 \\
\hline \multicolumn{3}{|c|}{ Taken drugs for parasitic infection } \\
\hline No & 61.3 & 26908 \\
\hline Yes & 56.5 & 3079 \\
\hline
\end{tabular}


Table 1 | Continued

\begin{tabular}{|c|c|c|}
\hline \multirow[t]{2}{*}{ Characteristics } & \multicolumn{2}{|c|}{ Anemia in children under- 5} \\
\hline & $\%$ & $N$ \\
\hline \multicolumn{3}{|l|}{ Socio-economic } \\
\hline \multicolumn{3}{|l|}{ Place of residence } \\
\hline Urban & 56.0 & 6956 \\
\hline Rural & 62.4 & 24005 \\
\hline \multicolumn{3}{|l|}{ Caste } \\
\hline Others & 57.6 & 7965 \\
\hline $\mathrm{OBC}$ & 62.8 & 6962 \\
\hline SC & 72.4 & 3723 \\
\hline ST & 59.2 & 12646 \\
\hline \multicolumn{3}{|l|}{ Religion } \\
\hline Hindu & 61.1 & 25583 \\
\hline Muslim & 61.6 & 6349 \\
\hline Others & 57.4 & 1372 \\
\hline \multicolumn{3}{|l|}{ Mother's education } \\
\hline No education & 66.5 & 6945 \\
\hline Primary & 63.6 & 2592 \\
\hline Secondary and above & 55.7 & 7001 \\
\hline \multicolumn{3}{|l|}{ Mother's working status } \\
\hline Not working & 60.6 & 22539 \\
\hline Working & 61.9 & 9775 \\
\hline \multicolumn{3}{|l|}{ Wealth index } \\
\hline Rich & 53.5 & 9037 \\
\hline Middle & 61.3 & 6484 \\
\hline Poor & 65.7 & 16820 \\
\hline \multicolumn{3}{|l|}{ Region } \\
\hline North & 56.5 & 3980 \\
\hline Central & 57.9 & 8933 \\
\hline East and north east & 69.7 & 10956 \\
\hline West & 56.3 & 3644 \\
\hline South & 57.6 & 4827 \\
\hline \multicolumn{3}{|c|}{ Media exposure of mother } \\
\hline \multicolumn{3}{|c|}{ Read newspaper or magazine } \\
\hline No & 63.6 & 24981 \\
\hline Yes & 53.5 & 7330 \\
\hline \multicolumn{3}{|l|}{ Watch television } \\
\hline No & 65.2 & 15968 \\
\hline Yes & 57.4 & 16371 \\
\hline \multicolumn{3}{|l|}{ Listen radio } \\
\hline No & 62.3 & 19967 \\
\hline Yes & 59.0 & 12370 \\
\hline
\end{tabular}

Figure 4 shows the percentage of children under the age of five years having anemia by place of residence according to sex (NFHS3 ). The figure interprets that in both urban and rural regions of India, female children have higher percentage of anemia than male children which is also true for India as a whole.

Figure 5 shows the significant odds of suffering anemia by major household environment determinants. It is inferred that with toilet facility available, pucca house and clean fuel, the odds
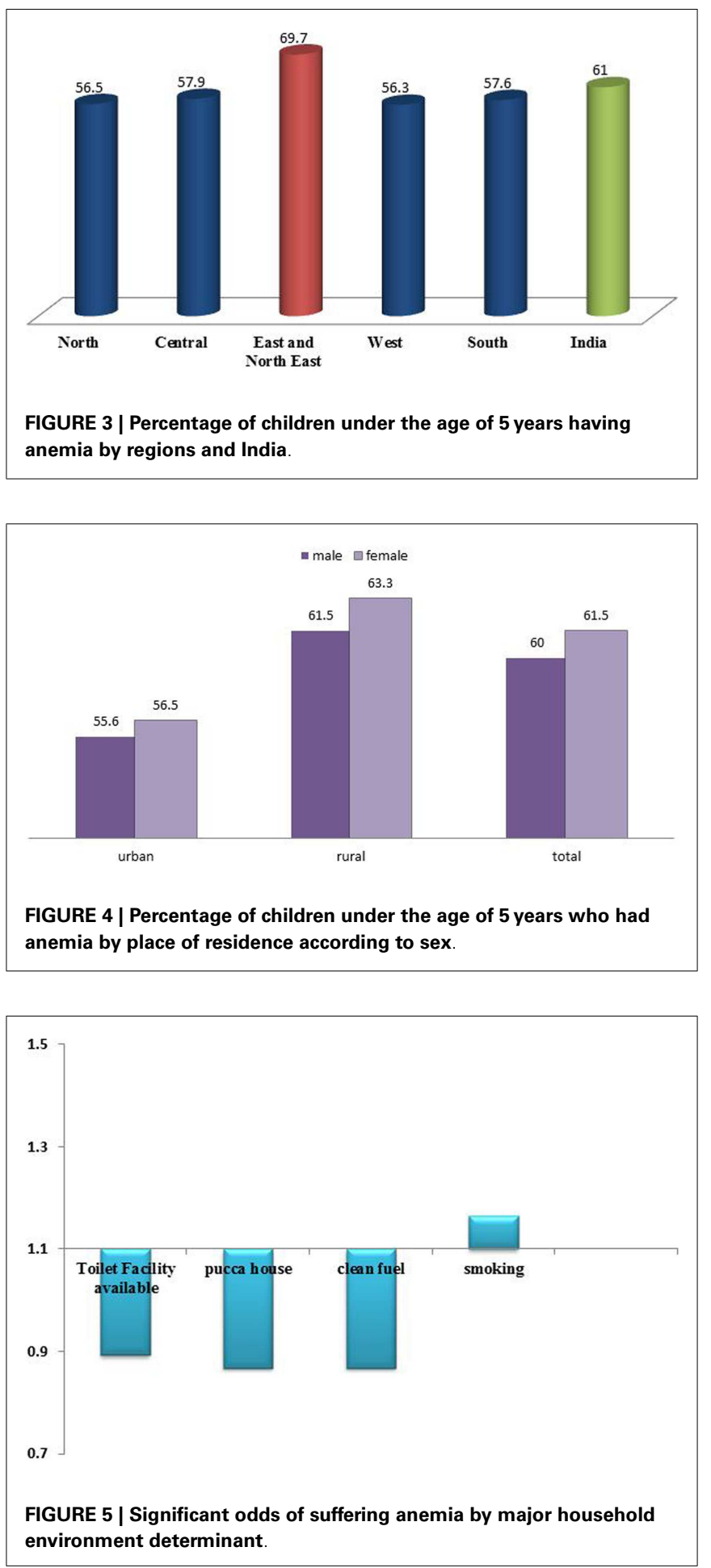

of anemia in children under five years are decreasing while odds are increasing in case of smoking.

\section{MULTIVARIATE ANALYSIS}

Table 2 shows the odds ratio of multivariate regression analysis based on children aged under 5 years of age. Among the environmental variables, in all the four regression models, it was seen that 
Table 2 | Regression models showing odds of having anemia among children $<5$ years.

\begin{tabular}{ll}
\hline Characteristics & Anemia in children under-5 \\
\cline { 2 - 2 } & Model 1 Model 2 Model 3 Model 4
\end{tabular}

\section{Environmental}

Toilet facility

No facility $®$

Facility available

Type of house

Kaccha ${ }^{\circledR}$

Semi pucca

Pucca

Type of cooking fuel

Unclean fuel ${ }^{\circledR}$

Clean fuel

House structure

Nuclear ${ }^{\circledR}$

Non-nuclear

Source of drinking water

Improved $₫$

Not improved

Smoking (anyone in the house) No ${ }^{\circledR}$

Yes

Seasonality

Winter ${ }^{\circledR}$

Summer and rainy

Child

Sex of child

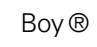

Girl

Age of child (months)

Less than 6 months $\AA$

6-23 months

24-59 months

Birth order of child

$$
\begin{aligned}
& 2 \\
& 3 \\
& 4
\end{aligned}
$$$$
1 \circledast
$$

Stunting

Stunting ${ }^{\circledR}$

Normal

Breastfeeding

Never breastfed ${ }^{\circledR}$

$<6$ months

6 months and above

Still breastfeeding

Taken drugs for parasitic infection No ${ }^{\circledR}$

Yes

$0.825^{* * *} 0.836 * * 0.880 \quad 0.893^{* * *}$

$0.896 * * 0.897^{* * *} 0.931 * * 0.935^{* *}$

$\begin{array}{llll}0.985 & 0.996 & 0.923 & 0.945\end{array}$

$0.882 \quad 0.884 \quad 1.164 * * * 1.164 * * *$

$\begin{array}{llll}0.994 & 1.009 & 0.954 & 0.957\end{array}$

$\begin{array}{lll}1.056 & 1.118 & 1.127 \\ 0.957 & 0.985 & 0.991 \\ 0.978 & 0.924 & 0.929\end{array}$

$-$
$0.893^{* *} 0.832 * * 0.838^{* * *}$

\section{Characteristics}

Anemia in children under-5

Model 1 Model $2 \quad$ Model $3 \quad$ Model 4

\section{Socio-economic}

Place of residence

Urban ${ }^{\circledR}$

Rural

Caste

Others ${ }^{\circledR}$

$\mathrm{OBC}$

$\mathrm{SC}$

ST

Religion

Others ${ }^{\circledR}$

Hindu

Muslim

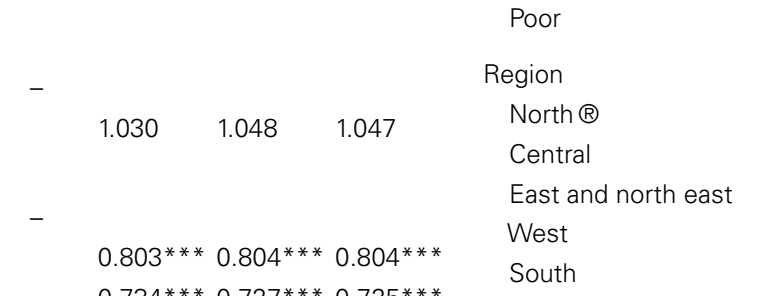

Media exposure of mother

Read newspaper or magazine

$$
\text { No }{ }^{\circledR}
$$

Yes

Watch television

No ${ }^{\circledR}$

Yes

Listen radio

No ${ }^{\circledR}$

Yes

Constant

$R^{2}$

N
$1.003 \quad 0.996$

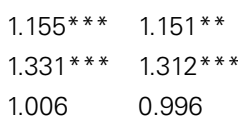

$1.006 \quad 0.996$

$1.622 * * * \quad 1.602 * * *$

$1.552 * * * 1.509 * * *$

$0.918 * * \quad 0.973$

$0.776 * * * 0.875$

$0.942 * * 0.949$

$1.015 \quad 0.980$

$1.125 * * 1.057$

$0.926 \quad 0.953$

$1.360 * * * 1.383 * * *$

$1.077 \quad 1.098^{* *}$

$1.091 * * 1.124 * *$
Q $\mathrm{R}$ reference category.

${ }^{*} p<0.10$.

${ }^{* *} p<0.05$.

${ }^{* * *} p<0.01$. 
the odds of anemia among children living in households that had toilet facility had decreased as compared to the households, which had no such facility available. Similar results were found for the type of house and type of cooking fuel. Children living in pucca houses had a lower likelihood of anemia as compared to those living in Kaccha houses. Use of clean cooking fuel also reduced the chances of anemia among children significantly. Children that belonged to non-nuclear families had significantly lower chance of anemia compared to nuclear families. Improved or non-improved source of drinking water did not show any significant impact on the prevalence of anemia. After adjusting for socio-economic factors, smoking did not show any significant impact on anemia while adjusting with other factors smoking showed an increased impact on anemia among children. Seasonality did not show any noticeable impact on anemia.

Among the child variables, there were no significant odds of anemia by gender but with the increased age of children there was a significant decrease in the likeliness of anemia among children. With the increased birth order there was no change in the odds of anemia except in the fourth model where significant odds were found in the third birth order. There was not much difference in anemia prevalence among children with normal or stunted development. Similarly, the duration of breastfeeding also did not seem to affect the prevalence of anemia. Children who had taken drugs taken for parasitic infections, in the 6 months prior to the data collection, showed a decreased likelihood of anemia. Among the socio-economic variables, there was no impact of place of residence on anemia. There was a higher prevalence of anemia among OBC (Other Backward Classes) and SC (Schedule Caste) castes as compared to general castes. ST showed no significant change in odds of anemia. Hindu and Muslim children showed higher odds of being anemic than others. With the increased educational level of mother, there were reduced odds of anemia among children but this was not found in model 4 . The working status of the mother had no significant impact on anemia. The poor showed higher chances of being anemic than the rich. Children in east, north east, and in southern regions showed significantly higher chances of anemia than those in other regions. Among the media exposure variables, there were significantly decreasing odds of anemia among those children whose mothers read newspaper, watched television, and listened to radio.

\section{DISCUSSION}

According to the World Health Organization (WHO); "anaemia is a condition in which the number of red blood cells and in turn their oxygen-carrying capacity is insufficient to meet the bodies physiologic needs" (5). From the present study, it was found that unclean fuel use, poor toilet facility, staying in non-concrete house, and smoking were important environmental variables determining anemia among children $<5$ years (6). According to National Rural Health Mission, India, poor environmental sanitation, unsafe drinking water, and inadequate personal hygiene conditions are some of the contributing factors toward anemia prevalence. The North and Eastern regions experienced significantly higher probability of having childhood anemia compared to all other regions of India (6). Report also states that more than half of the young children in 24 states of India have anemia, including 11 states where more than two third of children are anemic. Children who took drugs for parasitic infections showed lesser anemia prevalence in this study. National Rural Health Mission, India also confirms that parasitic infections like malaria and intestinal worms are one of the reasons for anemia among children in India (6). Anemia prevalence was found to be significantly higher in nuclear families. This could be because there is less number of members in the nuclear families to take care of children or because of the hectic schedule of family members. As a result, children do not get proper attention for food and nutrition. It was found smoking done by anybody in the house is significantly associated with child anemia. It is also evident from other studies that passive smoking in the household increases the risk of anemia in children (7).

\section{CONCLUSION}

This study found that unclean fuel use, poor toilet facility, staying in non-concrete house, and passive smoking are the major determinants. Unclean fuel use mainly affects the health of preschool children as they are more exposed to it. These children generally stay inside the households and are often carried by the mothers while cooking. Biofuel smoke contains high quantities of carbon monoxide, which binds with hemoglobin (transit oxygen to body tissues), forms carboxy hemoglobin, and reduces the oxygen-carrying capacity of hemoglobin, which leads to anemia. Clean drinking water, maintenance of sanitation, and hygiene practices contribute toward reducing anemia as they reduce parasitic infections among children. Therefore, there are multiple threats to anemia among children under the age of 5 years. Better resources are needed to educate the public and to increase awareness for improved hygiene, sanitation and housing facilities, health, and nutrition. Promoting and disseminating knowledge about the ill effects of passive smoking on the health of children can be an intellectual step toward it. Along with a wider program to manage nutritional deficiency anemia in children $<5$ years, there should be a holistic approach toward anemia control inculcating healthier household environmental conditions and improved socio economic factors.

\section{ACKNOWLEDGMENTS}

This research will be incomplete without the mention of all those people without the support of whom this research would have not been possible. First of all, we would like to express our heartfelt gratitude toward our project head, Prof. Thiagarajan Jayaraman, Dean, School of Habitat Studies, Tata Institute of Social Sciences, Mumbai, who has given his full support and encouragement throughout this endeavor. We are highly grateful to Elizabeth Weber, for the financial support for the resource hub and for research officer's salaries without which this project would have been impossible and lastly we are very much thankful to Mr. Ankit Anand and Dr. Joanne Michele Mascarenhas for their support, guidance, and help.

\section{REFERENCES}

1. International Institute for Population Sciences (IIPS), Macro International. National Family Health Survey (NFHS-3) 2005-06, India: Key Findings. Mumbai, India: IIPS (2007). 
2. Benoist B, McLean E, Egli I, Cogswell M, editors. Worldwide Prevalence of Anaemia 1993-2005: WHO Global Database on Anaemia. Geneva, USA: World Health Organization Publication (2008).

3. Sanou D, Ngnie-Teta I. Risk factors for anemia in preschool children in sub-Saharan Africa. In: Donald S, editor. Anemia. (2012). Available from: http://www.intechopen.com/books/anemia/risk-factors-for-anemiain-preschool-children-in-sub-saharan-africa

4. World Health Organization. Children's Health and the Environment Annual Report-2010. Geneva, USA: World Health Organization (2010).

5. World Health Organization. Haemoglobin Concentration for the Diagnosis of Anaemia and Assessment of Severity. Geneva, USA: World Health Organization (2011).

6. Guidelines for Control of Iron Deficiency Anaemia. National Rural Health Mission (2013).

7. Maternal and environmental factors affecting the nutritional status of children in Mumbai urban slum. Int J Sci Res Publ (2012) 2(11):1-9. Available from: http://www.ijsrp.org/research-paper-1112/ijsrp-p1112.pdf. doi:10.1.1.299.6521
Conflict of Interest Statement: The authors declare that the research was conducted in the absence of any commercial or financial relationships that could be construed as a potential conflict of interest.

Received: 15 July 2014; accepted: 30 September 2014; published online: 20 October 2014.

Citation: Baranwal A, Baranwal A and Roy N (2014) Association of household environment and prevalence of anemia among children under-5 in India. Front. Public Health 2:196. doi: 10.3389/fpubh.2014.00196

This article was submitted to Child Health and Human Development, a section of the journal Frontiers in Public Health.

Copyright (C) 2014 Baranwal, Baranwal and Roy. This is an open-access article distributed under the terms of the Creative Commons Attribution License (CC BY). The use, distribution or reproduction in other forums is permitted, provided the original author(s) or licensor are credited and that the original publication in this journal is cited, in accordance with accepted academic practice. No use, distribution or reproduction is permitted which does not comply with these terms. 